\title{
C-reactive protein binding to FcyRIIa on human monocytes and neutrophils is allele-specific
}

\author{
Mary-Pat Stein, ${ }^{1}$ Jeffrey C. Edberg, ${ }^{2}$ Robert P. Kimberly, ${ }^{2}$ Erin K. Mangan, ${ }^{2}$ \\ Dwaipayan Bharadwaj, ${ }^{1}$ Carolyn Mold, ${ }^{3}$ and Terry W. Du Clos ${ }^{1,3,4}$
}

${ }^{1}$ Department of Medicine, University of New Mexico School of Medicine, Albuquerque, New Mexico 87108, USA
${ }^{2}$ Department of Medicine, University of Alabama-Birmingham, Birmingham, Alabama, 35294, USA
${ }^{3}$ Department of Molecular Genetics and Microbiology, University of New Mexico School of Medicine,
Albuquerque, New Mexico 87131, USA
${ }^{4}$ Department of Medicine, Veterans Affairs Medical Center, Albuquerque, New Mexico 87108, USA

Address correspondence to: Terry W. Du Clos, Veterans Affairs Medical Center, Research Service 151, 1501 San Pedro SE, Albuquerque, New Mexico 87108, USA. Phone: (505) 256-5717; Fax: (505) 256-2794; E-mail: tduclos@unm.edu.

Received for publication July 12, 1999, and accepted in revised form December 14, 1999.

C-reactive protein (CRP) is involved in host defense, regulation of inflammation, and modulation of autoimmune disease. Although the presence of receptors for CRP on phagocytes has been inferred for years, their identity was determined only recently. Fc $\gamma R$ Ia, the high-affinity IgG receptor, binds CRP with low affinity, whereas Fc $\gamma$ RIIa, the low-affinity IgG receptor, binds CRP with high affinity. Because the single nucleotide polymorphism in Fc $\gamma \mathrm{RIIA}$ - which encodes histidine or arginine at position 131 - strongly influences IgG2 binding, we determined this polymorphism's effect on CRP binding. CRP bound with high avidity to monocytes and neutrophils from Fc $\gamma$ RIIA R-131 homozygotes, and binding was inhibited by the R-specific mAb 41H16. CRP showed decreased binding to cells from Fc $\gamma$ RIIA $\mathrm{H}-131$ homozygotes (which bind IgG2 with high affinity). However, IFN- $\gamma$ enhanced Fc $\gamma \mathrm{RI}$ expression by $\mathrm{H}-131$ monocytes and increased CRP binding. Fc $\gamma \mathrm{RII}$ a heterozygotes showed intermediate binding. CRP initiated increases in $\left[\mathrm{Ca}^{2+}\right]_{i}$ in PMN from R-131, but not from H-131 homozygotes. These data provide direct genetic evidence for Fc $\gamma$ RIIa as the functional, high-affinity CRP receptor on leukocytes while emphasizing the reciprocal relationship between IgG and CRP binding avidities. This counterbalance may affect the contribution of Fc $\gamma$ RIIA alleles to host defense and autoimmunity.

J. Clin. Invest. 105:369-376 (2000).

\section{Introduction}

C-reactive protein (CRP) is the prototypic acute phase serum protein in humans (1). Serum levels of CRP can increase 1,000-fold from baseline concentrations of less than $1 \mu \mathrm{g} / \mathrm{mL}$ in response to tissue damage, infection, or inflammation. CRP is a highly conserved member of the pentraxin family of proteins (2). Pentraxins share not only significant sequence and structural homology but also $\mathrm{Ca}^{2+}$-dependent ligand-binding activity. Both the evolutionary conservation of CRP as well as its dramatic upregulation in response to inflammatory mediators suggest that $\mathrm{CRP}$ has an important role in host defense and inflammation.

CRP shares several functional activities with IgG, including opsonization (3-5), complement activation by binding $\mathrm{C} 1 \mathrm{q}(6)$, and binding to $\mathrm{F} \gamma \gamma$ receptors $(\mathrm{Fc} \gamma \mathrm{R})$ $(7,8)$. Early work demonstrated that CRP facilitated the binding and phagocytosis of C-polysaccharide-coated sheep erythrocytes by human monocytes in the presence of a complement (3). Binding and phagocytosis were both inhibited by aggregated human IgG (aggIgG), which suggested that FcyR played a role. Subsequently, CRP binding to 2 distinct receptors on a monocytic cell line (U-937) was described (9). CRP binding was inhibited by aggIgG, yet CRP failed to inhibit aggIgG binding. Similarly, adherence of mono- cytes to IgG eliminated CRP-dependent rosetting, but the reverse was not true (10). Therefore, it was concluded that the CRP-specific receptor was distinct from Fc $\gamma R$ on human monocytes.

Our laboratory was the first to describe CRP binding to FcyRI on U-937 cells (7). We subsequently described CRP binding to Fc $\gamma R I$-transfected COS cells (8). CRP bound to Fc $\gamma R I$ with low affinity $\left(K_{d}=6 \times 10^{-6} \mathrm{M}\right)$, suggesting that an additional higher-affinity receptor accounted for the majority of CRP binding to human monocytes. In addition, CRP bound to K562 cells that express Fc $\gamma R$ RI as their only Fc $\gamma R$ (8). A review of the literature showed complete overlap between cell types and cell lines binding CRP and those expressing FcyRIIa. Recently, we demonstrated that CRP binds to human FcyRIIa on transfected COS cells with an affinity of 6.6 $\times 10^{-8} \mathrm{M}$ (11). CRP binding to Fc $\gamma$ RIIa-expressing COS cells was completely inhibited by aggIgG, which was consistent with earlier results. These findings suggest that Fc $\gamma$ RIIa is the major receptor for CRP on human monocytes and polymorphonuclear leukocytes (PMN).

In our experience, however, the binding of CRP to monocytes and PMN from different donors is extremely variable, which suggests a heterogeneity in the level or availability of receptors among donors. Direct assessment of CRP binding differences among donors 
did not demonstrate any relationship to the level of expression of either Fc $\gamma \mathrm{RI}$ or FcyRIIa. Therefore, we hypothesized that the variability in CRP binding may correspond to the single nucleotide polymorphism in human Fc $\gamma$ RIIA. This polymorphism produces a single amino acid difference - arginine $(\mathrm{R})$ or histidine $(\mathrm{H})$ at position 131 (12). These Fc $\gamma$ RIIa alleles show a variability in binding of human IgG2 (13) and murine IgG1 (14). The H-131 allele is the only human FcyR to bind human IgG2 efficiently (15).

In this article, we present the first direct experimental evidence that FcyRIIa is the functional high-affinity receptor for CRP on peripheral blood PMN and monocytes. Furthermore, CRP binding to monocytes and PMN was clearly evident in cells from donors with the R-131 allele of Fc $\gamma$ RIIa with only minimal binding to cells from donors homozygous for the $\mathrm{H}-131$ allele. Binding of CRP to Fc $\gamma$ RIIa-R-131 was inhibited by $\mathrm{mAb}$ 41H16, which is specific for the R-131 form of FcyRIIa. CRP binding to monocytes from $\mathrm{H}-131$ homozygous donors could be induced after culture in IFN- $\gamma$ and upregulation of FcyRI expression. Pronase treatment of monocytes or PMN to activate FcyRIIa did enhance CRP binding, but did not abrogate the differences in binding of CRP to the R-131 and H-131 alleles of FcyRIIa. These data not only provide direct genetic evidence for Fc $\gamma$ RIIa as the major, high-affinity receptor for CRP in human phagocytes, but they also demonstrate the importance of both the cytokine environment and allelic variations in receptor structure in determining the host response to CRP. These findings may have important consequences in studies of host defense and risk for autoimmunity.

\section{Methods}

Reagents and antibodies. Human CRP was purified from human pleural fluids exactly as previously described (16). The purity of the preparation was determined by $12 \%$ SDS-PAGE. No contaminating proteins were detected on overloaded gels. Essentially Ig-free BSA, HBSS without calcium or magnesium (HBSS-), and pronase were purchased from Sigma (St. Louis, Missouri, USA). Recombinant human IFN- $\gamma$ was provided by Genentech Inc. (South San Francisco, California, USA). The anti-CRP mAb 2C10 (a mouse IgG1 $\mathrm{mAb}$ ) was generously provided by Larry Potempa (ImmTech International Inc., Evanston, Illinois, USA) and was FITC conjugated in our laboratory. A control mouse IgG1 was purchased from Sigma and was used as a control for the $2 \mathrm{C} 10 \mathrm{mAb}$. The anti-Fc $\gamma \mathrm{RII} \mathrm{mAb}$ $41 \mathrm{H} 16$ was generously provided by Thomas Zipf (University of Texas Cancer Center, Houston, Texas, USA) (17). Isotype controls for MIgG2a were obtained from Sigma and PharMingen (San Diego, California, USA). Anti-Fc $\gamma R$ antibodies were purchased as follows: FITC anti-CD64 (mAb 10.1), FITC anti-CD16 (mAb 3G8) from PharMingen; anti-CD64 (mAb 32.2), anti-CD32 (mAb IV.3, IgG, and Fab), and anti-CD16 (mAb 3G8) from Medarex Inc. (Annandale, New Jersey, USA); and phycoerythrin (PE) anti-CD32 (mAb C1KM5) from Caltag Laboratories Inc. (Burlingame, California, USA). Lymphocyte markers were anti-CD56 (natural killer (NK)) (Becton-Dickinson Immunocytometry Systems, San Jose, California, USA), anti-CD19 (B cells), and anti-CD3 ( $\mathrm{T}$ cells) (Caltag Laboratories Inc.). PE-conjugated $\mathrm{F}\left(\mathrm{ab}^{\prime}\right)_{2}$ goat anti-mouse IgG (PEGAM) and PE-conjugated $\mathrm{F}\left(\mathrm{ab}^{\prime}\right)_{2}$ goat anti-rabbit IgG were from Caltag Laboratories Inc. $\mathrm{F}\left(\mathrm{ab}^{\prime}\right)_{2}$ goat antimouse IgG (GAM) was from TAGO Inc. (Burlingame, California, USA). A rabbit anti-CRP antibody was prepared in our laboratory, and IgG was purified by protein A affinity chromatography.
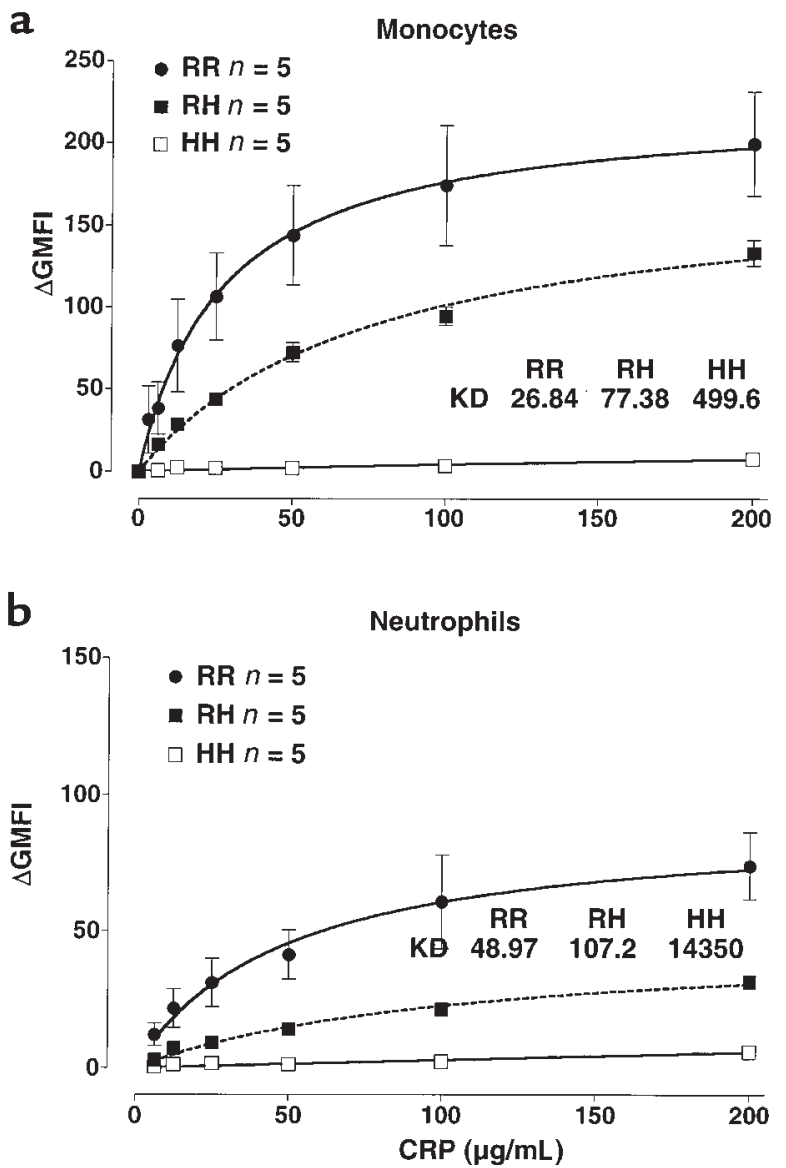

Figure 1

CRP binding to human monocytes and PMN is FcyRlla allele-specific. Human monocytes and PMN from genotyped donors were isolated from peripheral blood by gradient separation using Mono-Poly Resolving Medium. Cells were washed in ice-cold PAB and incubated in the presence of CRP for 60 minutes on ice. After 2 washes, bound CRP was detected by flow cytometry using mAb 2C10 and PE-GAM. (a) CRP binding to PMN from R-131 homozygotes, $\mathrm{R} / \mathrm{H}-131$ heterozygotes, and $\mathrm{H}-131$ homozygotes. (b) CRP binding to monocytes from R-131 homozygotes, R/H-131 heterozygotes, and $\mathrm{H}-131$ homozygotes. Results are expressed as the change in GMFI. Data were analyzed by Student's paired $t$-test and two-tailed $P$ values were calculated using GraphPad Prism software. The $P$ values for RR versus $\mathrm{HH}$, RR versus $\mathrm{RH}$, and $\mathrm{RH}$ versus $\mathrm{HH}$ monocytes were $0.004,0.001$, and 0.015 , respectively. The $P$ values for RR versus $\mathrm{HH}$, RR versus $\mathrm{RH}$, and $\mathrm{RH}$ versus $\mathrm{HH}$ neutrophils were $0.008,0.005$, and 0.018 , respectively. 
Genotyping of $F c \gamma R$ alleles. Genomic DNA was extracted from EDTA anticoagulated whole blood (Gentra Systems Inc., Plymouth, Minnesota, USA). For Fc $\gamma$ R genotype determinations, we used allele-specific PCR reactions to characterize the presence or absence of the $\mathrm{H}-131 / \mathrm{R}-131$ alleles of FcrRIIA, the NA1/NA2 alleles of FcyRIIIB, and the F176/V176 alleles of FcyRIIIA $(18,19)$. For the Fc $\gamma$ RIIA alleles, a forward PCR primer was used to bind to a sequence in intron 4 that is unique to the FcyRIIA gene together with either H-131- or R-131-specific reverse primers as we have reported previously (19). For the FcyRIIIB alleles, we used a forward primer that binds to a sequence in intron 1 that is unique to the FcyRIIIB gene together with both NA1- and NA2-specific reverse primers in a multiplex PCR reaction. For the FcyRIIIA alleles, we used a forward FcyRIIIA-specific PCR primer that binds to a sequence in exon 4 together with either F159- or V159-specific reverse primers as we have reported previously (18).

Peripheral blood cells. Monocytes and neutrophils were obtained from peripheral blood of healthy volunteers by gradient separation using Mono-Poly Resolving Medium (ICN Pharmaceuticals, Aurora, Ohio, USA). Cells were washed twice in HBSS- before analysis for CRP binding. To increase expression of Fc $\gamma R$, peripheral blood mononuclear cells were isolated, resuspended in complete medium (RPMI-1640 with 10\% FCS and $50 \mu \mathrm{g} / \mathrm{mL}$ gentamicin), and then cultured for 48 hours in the presence of $200 \mathrm{U} / \mathrm{mL}$ recombinant human IFN$\gamma$ before analysis for Fc $\gamma$ R expression and CRP binding. In some experiments, isolated monocytes and PMN were incubated at a concentration of $5 \times 10^{6}$ cells $/ \mathrm{mL}$ with $50 \mu \mathrm{g} / \mathrm{mL}$ pronase for 30 minutes at $37^{\circ} \mathrm{C}$ before analysis of CRP binding.

FcyRIIIa-bound CRP was assessed on peripheral blood NK cells by multicolor flow cytometry using anti-CD56 to positively identify the NK cells (18). The CD56-positive cells were also shown to express CD16. In some experiments, anti-CD19 and anti-CD3 were included to exclude B and T lymphocytes.

CRP-binding assay. Cells were washed twice in PBS containing $0.1 \% \mathrm{BSA}$ and $0.05 \%$ sodium azide (PAB). Cells (3-10 $\times 10^{5}$ per sample) were incubated in CRP-containing $\mathrm{PAB}$ for 1 hour on ice. Cells were washed twice with $1 \mathrm{~mL} \mathrm{PAB}$ and then incubated on ice with 4 $\mu \mathrm{g} / \mathrm{mL}$ mAb 2C10 for 30 minutes. Cells were washed twice as before and then incubated for 30 minutes with $1 \mu \mathrm{g}$ per $10^{6}$ cells of PE-GAM, PE anti-CD32, FITC antiCD16, or FITC anti-CD64. Cells were washed and resuspended in PAB for analysis by flow cytometry. CRP binding was also determined using IgG rabbit anti-CRP and PE goat anti-rabbit IgG.

Anti-Fc $\gamma$ RIIa mAb blocking of CRP binding. Washed anticoagulated whole blood was prepared as described (20). Aliquots of the washed blood were incubated with the anti-FcyRIIa mAb $41 \mathrm{H} 16$ (17) or with a mIgG2a isotype control (clone UPC-10; Sigma) for 15 minutes at $4^{\circ} \mathrm{C}$. CRP $(100 \mu \mathrm{g} / \mathrm{mL})$ was added, and the
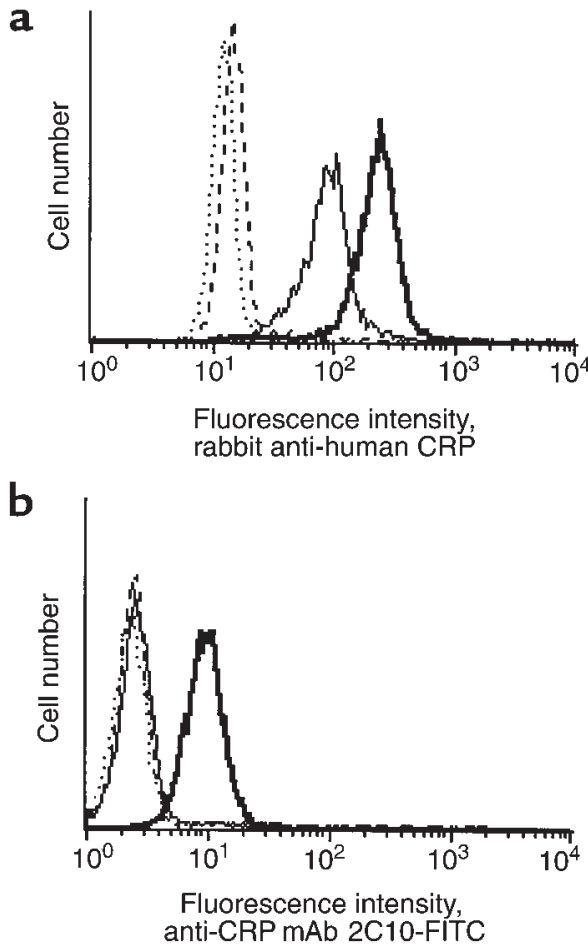

Figure 2

CRP binding to human PMN is FcyRlla allele-specific. Washed whole blood from Fc $\gamma$ RII genotyped donors were incubated with CRP (solid lines) or with buffer as a control (dashed lines), and CRP binding was detected with either a polyclonal rabbit anti-CRP antibody (a) or with mAb 2C10-FITC for comparison (b). PMN were selected based on characteristic light scattering properties, and binding of the respective Abs to an R-131/R-131 donor (thick lines) and to an H-131/H-131 donor (thin lines) is shown. Four independent experiments were performed using different donor pairs. The magnitude of the difference in binding of the rabbit anti-CRP antibody varied between the donor pairs (as did the level of FcyRlla expression), but the R-131/R-131 donors always bound more CRP than the $\mathrm{H}-131 / \mathrm{H}-131$ donors. The binding of an isotype control $\mathrm{mAb}$ was identical to the binding of 2C10-FITC in the absence of CRP.

incubation was continued for an additional $60 \mathrm{~min}$ utes. After 2 washes, bound CRP was detected with the anti-CRP mAb 2C10-FITC.

Flow cytometry. Cells were analyzed using a FACSCalibur flow cytometer (Becton Dickinson Immunocytometry Systems). Dead cells were excluded from analysis by forward and side scatter. In all measurements of CRP binding, background binding of 2C10 and PE-GAM has been subtracted. Values are reported as the change in geometric mean fluorescence intensity $(\Delta \mathrm{GMFI})$. Data were analyzed using GraphPad Prism software (GraphPad Software for Science Inc., San Diego, California, USA). Error bars denote the SEM as determined based on $n$ samples for each concentration of CRP.

Analysis of intracellular $\mathrm{Ca}^{2+}$ concentrations. Indo-1, a fluorescent dye with spectral properties that change with the binding of free $\mathrm{Ca}^{2+}$, was used to measure changes in intracellular calcium concentrations as we have described $(21,22)$. PMN were incubated at $37^{\circ} \mathrm{C}$ for 15 minutes with $5 \mu \mathrm{M}$ Indo- 1 acetoxymethylester (AM). After load- 


\section{a}

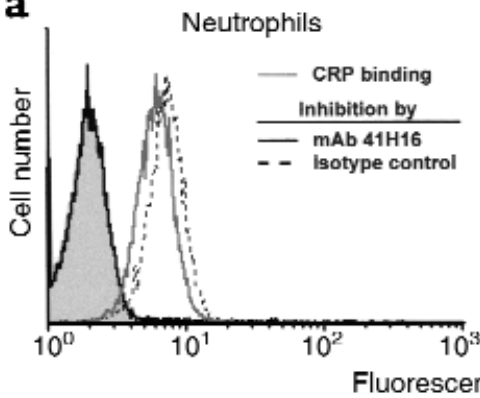

b

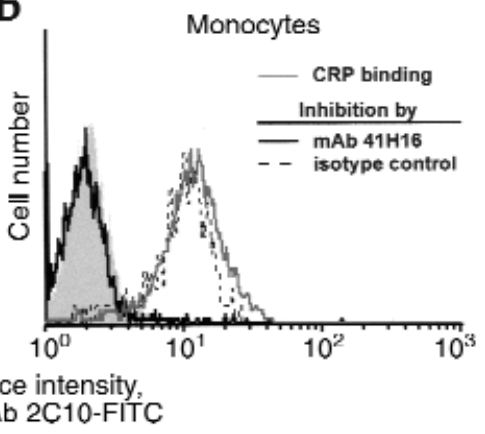

Figure 3

CRP binding to human monocytes and PMN from R-131 homozygous donors is inhibited by mAb 41H16. Washed, anticoagulated whole blood was prepared from R-131 homozygotes. Aliquots of the washed blood were incubated with the anti-FcyRlla mAb $41 \mathrm{H} 16$ or with a $\mathrm{mlgG} 2 \mathrm{a}$ isotype control for 15 minutes at $4^{\circ} \mathrm{C}$. CRP $(100 \mu \mathrm{g} / \mathrm{mL})$ was added, and the incubation was continued for an additional $60 \mathrm{~min}$. After 2 washes, bound CRP was detected with the anti-CRP mAb 2C10-FITC. The shaded area represents background binding of the mAb 2C10-FITC only. (a) Neutrophils; (b) monocytes.

ing, the cells were washed once with modified PBS (containing $5 \mathrm{mM} \mathrm{KCl}$ and $5 \mathrm{mM}$ glucose) and maintained at $25^{\circ} \mathrm{C}$ in the dark. In some samples, an aliquot of cells (at a concentration of $10^{7}$ cells $/ \mathrm{mL}$ ) was incubated with anti$\mathrm{CD} 32 \mathrm{mAb}$ IV.3 Fab for 5 minutes at $37^{\circ} \mathrm{C}$ followed by 1 wash at room temperature. The cells were then resuspended to $5 \times 10^{6}$ cells $/ \mathrm{mL}$ in modified PBS and then warmed to $37^{\circ} \mathrm{C}$ for 5 minutes in modified PBS, $1.1 \mathrm{mM}$ $\mathrm{Ca}^{2+}$, and $1.6 \mathrm{mM} \mathrm{Mg}^{2+}$ before analysis.

Indo-1 fluorescence analysis was performed on a spectrofluorometer (SLM 8000C; Spectronic Instruments Inc., Rochester, New York, USA). Excitation at $355 \mathrm{~nm}$ was provided by a xenon arc lamp and a monochromator, while emission at 405 and $490 \mathrm{~nm}$ were simultaneously monitored with 2 monochromators and photo multiplier tubes. A corresponding stimulus was injected into each cuvette at 60 seconds without interruption of acquisition. Constant temperature $\left(37^{\circ} \mathrm{C}\right)$ and stirring were maintained throughout each experiment. Each sample was individually calibrated for both maximum and minimum Indo- 1 fluorescence by sequential addition of Triton X-100 and EDTA, and the $405 / 490 \mathrm{~nm}$ ratio was converted to $\left[\mathrm{Ca}^{2+}\right]$ as previously described $(21,22)$.

\section{Results}

Analysis of CRP binding to buman monocytes and PMN. Peripheral blood monocytes and PMN from healthy volunteers of known Fc $\gamma$ RIIA genotype were tested for CRP binding using a flow cytometric assay. CRP binding to monocytes from R-131 homozygotes and R/H131 heterozygotes was dose dependent and saturable at approximately $100 \mu \mathrm{g} / \mathrm{mL}$ of CRP. Monocytes from R131 homozygotes bound CRP with an apparent $K_{\mathrm{d}}$ of $27 \mu \mathrm{g} / \mathrm{mL}\left(2.4 \times 10^{-7} \mathrm{M}\right)$, whereas monocytes from heterozygotes bound CRP with an apparent $K_{\mathrm{d}}$ of 77 $\mu \mathrm{g} / \mathrm{mL}\left(7.0 \times 10^{-7} \mathrm{M}\right)$ (Figure 1a). The binding avidity of CRP for monocytes from heterozygous donors compared with monocytes from R-131 homozygous donors was thus decreased by $65 \%$. CRP binding to monocytes from $\mathrm{H}-131$ homozygotes was not detected. The pres-

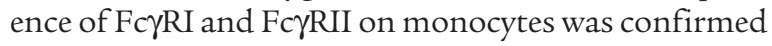
by staining with anti-CD64 and anti-CD32 mAb. Consistent with previous reports of Guyre et al. (23) who found 15,000-35,000 binding sites per cell for antiCD64, expression of FcyRI on monocytes was low. Levels of FcyRIII on monocytes were also low.

Similarly, CRP bound to human PMN from R-131 homozygous and $\mathrm{R} / \mathrm{H}-131$ heterozygous donors in a dose-dependent manner with saturation at approximately $100 \mu \mathrm{g} / \mathrm{mL}$ CRP (Figure 1b). CRP bound to PMN from R-131 homozygotes with an apparent $K_{\mathrm{d}}$ of $33 \mu \mathrm{g} / \mathrm{mL}\left(3.0 \times 10^{-7} \mathrm{M}\right)$; whereas it bound to PMN from $\mathrm{R} / \mathrm{H}-131$ heterozygous donors with an apparent $K_{\mathrm{d}}$ of $107 \mu \mathrm{g} / \mathrm{mL}\left(9.7 \times 10^{-7} \mathrm{M}\right)$. This represents a $70 \%$ decrease in CRP-binding avidity for PMN from $\mathrm{R} / \mathrm{H}$ 131 heterozygotes compared with PMN from $\mathrm{R} / \mathrm{H}-131$ heterozygotes. Once again, no binding of CRP was detected to PMN from H-131 homozygotes. The presence of FcyRII and FcyRIII on PMN was confirmed by staining with anti-CD32 and anti-CD16 mAb. There were no consistent differences in the levels of all 3 classes of FcyR on monocytes and PMN between R-131 homozygous, $\mathrm{R} / \mathrm{H}$ heterozygous, and $\mathrm{H}-131$ homozygous donors, consistent with previous data (17).

Because mouse IgG1 could potentially be differentially bound to the 2 allelic forms of FcRII, the preferential binding of CRP to the $\mathrm{R}$ allotype was verified using an independent binding assay. We have previously shown that the binding of rabbit IgG is insensitive to the H-131/R-131 alleles of FcyRIIa (24). Accordingly, we used a rabbit polyclonal anti-CRP antibody as the primary detecting reagent, and a PE-conjugated goat antirabbit IgG was used as the labeled secondary antibody. The preferential binding of CRP to the R-131 allotype was confirmed (Figure 2a). As a comparison, the binding of mAb 2C10-FITC to neutrophils from the same donors is shown in Figure 2b. The apparent level of binding of CRP to both FcyRIIa alleles is higher using the rabbit polyclonal anti-CRP because of a more effi- 
cient detection strategy. Thus, there is evidence that CRP binds to the H-131 allele of Fc $\gamma$ RIIa, however the quantitative level of binding is significantly less than that observed with the R-131 allele of FcyRIIa (25).

Inhibition of CRP binding to human PMN by mAb 41H16. The CRP binding specificity to the R allele of Fc $\gamma$ RIIa was confirmed with the anti-FcyRII mAb 41H16. This mAb binds to Fc $\gamma$ RIIa R-131, but not to Fc $\gamma$ RIIa H-131, and it blocks the ligand-binding site of the R-131 allele (17). Preincubation of whole blood with a saturating dose of $\mathrm{mAb} 41 \mathrm{H} 16$ - but not an isotype control completely blocked the binding of CRP to PMN and monocytes from R-131 homozygous donors (Figure 3). We and others have previously shown that mAb IV.3, which completely blocks IgG binding, does not inhibit CRP binding $(7,9)$. However, mAb IV.3 is insensitive to the H-131/R-131 polymorphism. Together, these results suggest that CRP binding to human peripheral blood monocytes and PMN requires the presence of the Fc $\gamma$ RIIa R-131 phenotype.

CRP induces an intracellular $\mathrm{Ca}^{2+}$ transient in an Fc $\gamma$ RIIa allele-dependent manner. To determine the functional consequences of the Fc $\gamma$ RIIa alleles on neutrophil activation by CRP, we analyzed the ability of CRP to induce an intracellular $\mathrm{Ca}^{2+}$ transient. We and others have shown that engagement and cross-linking of FcyRIIa on human PMN results in a rapid and transient rise in intracellular $\mathrm{Ca}^{2+}$ that is derived from intracellular stores (22). Accordingly, isolated human PMN from donors homozygous for either $\mathrm{H}$ or $\mathrm{R}$ were loaded with the $\mathrm{Ca}^{2+}$ sensitive dye Indo-1. After assessment of resting $\mathrm{Ca}^{2+} \mathrm{lev}$ els, CRP was added to the cells. A rapid and transient elevation in intracellular $\mathrm{Ca}^{2+}$ was observed in $\mathrm{PMN}$ from $\mathrm{R}-131$ homozygous donors, but none was observed in $\mathrm{H}$ 131 homozygous donors (Figure 4a). To verify that the PMN from the H-131 homozygous donor were functionally competent, separate aliquots of cells from all donors were stimulated with either $10^{-7} \mathrm{M}$ fMLP (results not shown) or with the anti-FcyRIIa mAb IV.3 Fab and $\mathrm{F}\left(\mathrm{ab}^{\prime}\right)_{2} \mathrm{GAM}$ (Figure $4 \mathrm{~b}$ ), and comparable $\mathrm{Ca}^{2+}$ transients were observed. Finally, CRP binding to the Indo- 1-loaded PMN was confirmed by flow cytometric analysis of aliquots of the cell suspensions which had been removed after completion of the $\mathrm{Ca}^{2+}$ transient. These results demonstrate that the $\mathrm{R}$ allele-specific binding of $\mathrm{CRP}$ is functionally relevant and results in the initiation of intracellular signaling events.

Analysis of CRP binding to Fc $\gamma R$ III. NK cells express FcyRIIIa, and 2 allelic forms of this receptor have been described with either phenylalanine (F) or valine (V) at position 176. To determine if CRP can bind to either of the alleles, whole blood from donors homozygous for either F176 or V176 were analyzed. NK cells were identified by a combination of characteristic light scatter properties and CD56 expression as we have described (18). No CRP binding was detectable on the CD56-positive cells from donors homozygous for either FcyRIIIa allele (Figure 5, a and b). Expression of FcyRIIIa on the CD56-positive cells was verified with an anti-CD16 mAb (Figure 5c). As a positive control, each donor was either R-131/R-131 or R-131/H-131 with respect to Fc $\gamma \mathrm{RIIa}$, and binding of CRP to monocytes and PMN was verified.

PMN express the glycosylphosphatidylinositolanchored receptor, FcyRIIIb, which has an allelic polymorphism, designated as NA1/NA2. PMN from all donors shown in Figure 2 expressed high levels of FcyRIIIb, measured using mAb 3G8. Little or no CRP binding was observed using PMN from H-131 homozygotes, which suggests that CRP does not bind to Fc $\gamma \mathrm{RI}-$ IIb. To eliminate possible allele-specific binding of CRP to FcyRIIIB, the genotypes of the $\mathrm{H}-131$ homozygotes, with respect to the NA1 and NA2 alleles of FcyRIIIb, were determined. Homozygous individuals of each type as well as heterozygous individuals were included in the $\mathrm{H}-131$ homozygotes shown. These results indicate that CRP does not bind to either FcyRIIIb allele.

CRP binding to $H-131 / H-131$ monocytes is enhanced by treatment with IFN- $\gamma$. Because we had previously demonstrated that CRP binds to Fc $\gamma R \mathrm{R}$ in transfected COS cells (8), it was expected that CRP would bind to Fc $\gamma \mathrm{RI}$ on monocytes. However, as shown in Figure 1a, there was little or no detectable CRP binding to freshly iso-

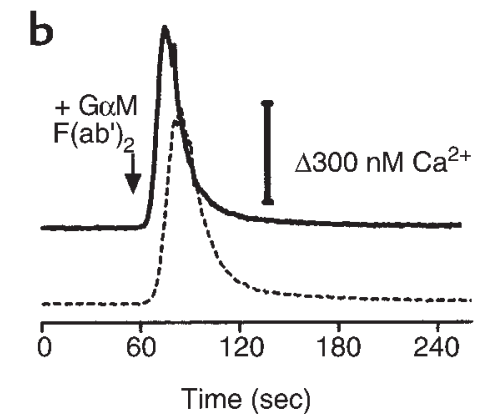

\section{Figure 4}

CRP induces a rise in intracellular [ $\left.\mathrm{Ca}^{2+}\right]$ in PMN in an FcyRlla allele-dependent manner. PMN were isolated and loaded with Indo-1-AM, and the $\left[\mathrm{Ca}^{2+}\right]$ was determined as described in Methods. $\mathbf{a}$ and $\mathbf{b}$ each show a representative experiment (from a total of 3 experiments) using PMN from an R-131/R-131 donor (solid line) and an H-131/H-131 donor (dashed line). (a) CRP $(100 \mu \mathrm{g} / \mathrm{mL}$ ) was added as a stimulus at 60 seconds. (b) Aliquots of PMN were pretreated with anti-FcyRII mAb IV. 3 Fab for 5 minutes at $37^{\circ} \mathrm{C}$. After 1 wash, cells were resuspended in buffer containing $\mathrm{Ca}^{2+} / \mathrm{Mg}^{2+}$ and incubated for 5 minutes at $37^{\circ} \mathrm{C}$ before analysis. GAM F(ab') $)_{2}$ was added as a stimulus at 60 seconds. 

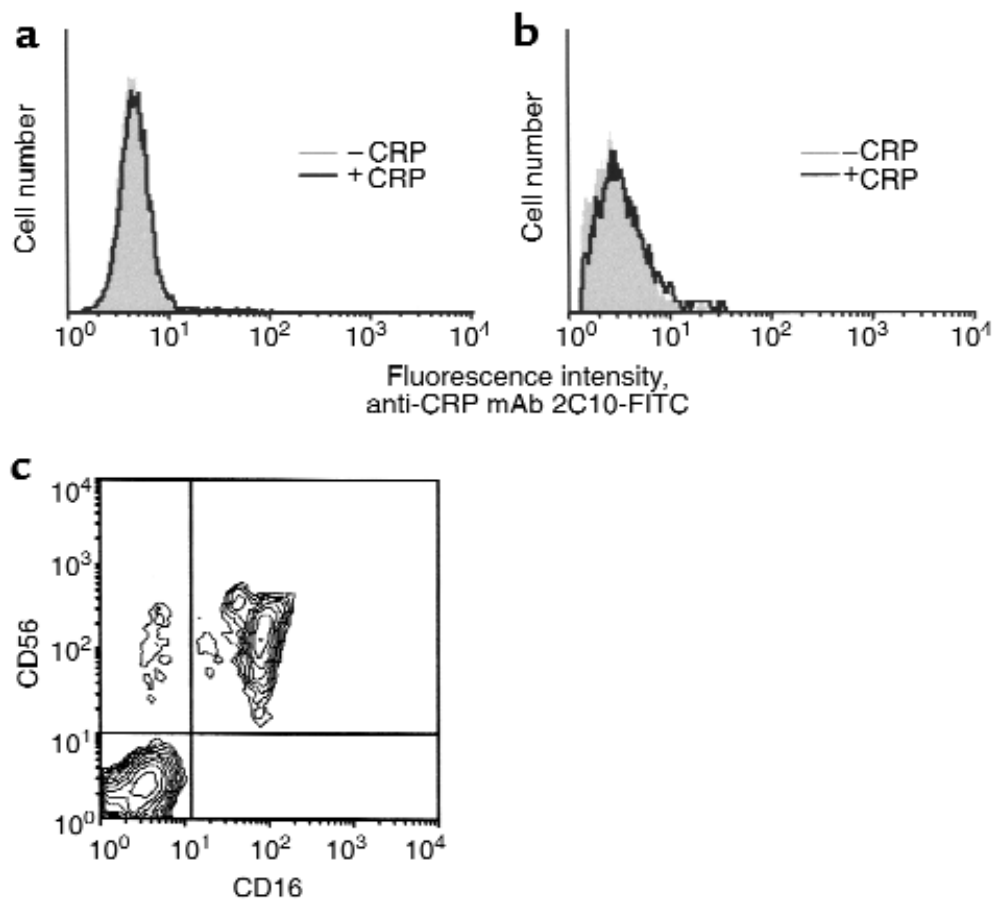

\section{Figure 5}

Binding of CRP to FcyRIIla on NK cells is not detectable. NK cells express Fc $\gamma R$ IIIla, and 2 allelic forms of this receptor have been described with either phenylalanine (F) or valine $(\mathrm{V})$ at position 176 . To determine if CRP can bind to either of these alleles, whole blood from donors homozygous for either F176 or V176 was analyzed. NK cells were identified by a combination of characteristic light scatter properties and CD56 expression. No binding of CRP was detectable on the CD56-positive cells from donors homozygous for either FcyRIIla allele. (a) CRP binding to F176 allele-bearing donor cells. (b) CRP binding to V176 allele-bearing donor cells. The shaded area is fluorescence with 2C10-FITC alone. (c) Histogram of cells analyzed in $\mathbf{a}$ and $\mathbf{b}$. The top right quarter of c, containing CD56+ and CD56+ cells, was selected for analysis by gating. lated monocytes from FcyRIIa H-131 homozygous donors. Staining with anti-FcyRI mAb 32.2 showed low levels of FcyRI expression on monocytes consistent with previous studies by Guyre et al. (23). It had been demonstrated previously that treatment with IFN- $\gamma$ upregulates the expression of Fc $\gamma \mathrm{RI}$ on monocytes (23). Therefore, peripheral blood mononuclear cells from $\mathrm{H}$ 131 homozygous donors were cultured in the presence or absence of IFN- $\gamma$ for 2 days, and CRP binding was measured by flow cytometry. Cells were gated by light scatter characteristics to exclude lymphocytes. After culture, monocytes/macrophages from H-131 homozygotes showed increased CRP binding, which was enhanced by IFN- $\gamma$ (Figure 6). CRP binding to these cells correlated with increased expression of Fc $\gamma \mathrm{RI}$ determined by binding of anti-CD64 (before culture GMFI 47, control culture GMFI 290, IFN- $\gamma$ culture GMFI 3,040). The level of CRP binding to IFN- $\gamma$-treated monocytes from $\mathrm{H}-131$ homozygous donors was similar to the level of CRP binding to unstimulated monocytes from R-131 homozygous donors. Thus, $\mathrm{CRP}$ binding to Fc $\gamma \mathrm{RI}$ is of increasing importance when monocytes are activated by inflammatory cytokines.

CRP binding to monocytes and PMN is enhanced by treatment with pronase. One unique characteristic of Fc $\gamma \mathrm{RIIa}$ is its enhanced binding of IgG after treatment of cells with serine proteases $(25,26)$. It has been shown that treatment of monocytes and cell lines with pronase can enhance IgG binding. We therefore tested the effect of pronase treatment of human monocytes and PMN on CRP binding. CRP binding to R-131/R-131 and R131/H-131 monocytes and PMN was markedly increased after pronase treatment (data not shown). However, CRP binding to PMN and monocytes from FcrRIIa H-131/H-131 donors was only slightly enhanced. Similar results were obtained using the rabbit anti-CRP-detecting antibody. Receptor numbers, excluding FcyRIIIb were not changed by pronase treatment as determined by mAb staining. Fc $\gamma \mathrm{RIIIb}$, which is known to be pronase sensitive, was largely removed. Therefore activation of PMN and monocytes at inflammatory sites does not alter the selectivity of CRP binding for the R-131 form of Fc $\gamma$ RIIa.

\section{Discussion}

CRP is the prototypic acute phase protein in humans (1). In animal models, CRP has been shown to protect against bacterial infection $(26,27)$, endotoxin shock (28), pulmonary inflammation (29), and autoimmune disease (30). CRP binds to bacterial polysaccharides (31), damaged membranes $(32,33)$, and nuclear antigens $(34,35)$. Its functional activity is believed to be mediated by complement activation and interaction with receptors on phagocytic cells. Monocytes, neutrophils, and myeloid cell lines have high- and low-affinity receptors for CRP (9). The relationship between the CRP receptors and Fc $\gamma R$ had been controversial for many years. Several years ago, we determined that CRP binds with low affinity to FcyRI $(7,8)$, and more recently, we found that CRP binds with high affinity to Fc $\gamma$ RIIa (11). Results using transfected COS cells and cell lines indicate that FcyRI and Fc $\gamma \mathrm{RII}$ are the major leukocyte receptors for CRP. This conclusion is supported by the inability of CRP to bind to peritoneal macrophages and PMN from mice lacking all 3 types of Fc $\gamma R$ (36).

Previous studies of CRP binding and activation of human peripheral blood leukocytes have produced contradictory results. We observed that the level of CRP binding to human monocytes and PMN differed among individuals. As allelic differences in Fc $\gamma$ RIIa, Fc $\gamma$ RIIIa, 
and FcyRIIIb can result in differential binding of IgG $(13,15,25)$, we investigated whether allelic differences in Fc $\gamma$ R could account for the differences in CRP binding among donors. CRP bound with high affinity to monocytes and neutrophils from donors with the R-131/R131 and R-131/H-131 genotypes of Fc $\gamma$ RIIa, which was as expected from our previous studies of CRP binding to cells transfected with the FcyRIIa plasmid. The relative decrease in CRP binding to the cells from individuals expressing the $\mathrm{H}$ allele of Fc $\gamma$ RIIa was unexpected. No evidence for CRP binding to alleles of Fc $\gamma$ RIIIa or Fc $\gamma R I-$ $\mathrm{IIb}$ was found. These data provide direct genetic evidence confirming the identity of Fc $\gamma$ RIIa as the major receptor for CRP on monocytes and PMN.

Consistent with the conclusion that the FcyRIIa-R131 allele is the major high-affinity receptor for CRP, binding to FcyRIIa-R-131 on peripheral blood leukocytes was completely inhibited by the mAb $41 \mathrm{H} 16$. This $\mathrm{mAb}$ binds to the R-131 allele but not the $\mathrm{H}-131$ allele of FcyRIIa, and it also blocks the binding of IgG to FcyRIIa-R-131 (17). Thus, the site of CRP binding to FcyRIIa is closely related to the site at which IgG binds to FcyRIIa. The anti-CD32 mAb IV.3, which blocks aggIgG binding, does not block CRP binding to cell lines $(7,9)$. However, as this $\mathrm{mAb}$ is not sensitive to the H-131/R-131 polymorphism, it must recognize a distinct but perhaps overlapping epitope on FcrRIIa relative to $\mathrm{mAb} 41 \mathrm{H} 16$. Therefore, the site of CRP binding to FcyRIIa is closely related to - but not identical tothe site at which IgG binds to Fc $\gamma$ RIIa.

The R-131 allele of FcrRIIa is associated with increased susceptibility to infection with certain encapsulated bacteria $(37,38)$. It has been postulated that these associations are the result of the decreased binding of IgG2 to the R-131 allele (39). IgG2 is the major subclass of antibody produced in response to polysaccharide antigens, including capsular polysaccharides of Streptococcus pneumoniae and Hemophilus influenza in children (40). CRP binds to several encapsulated bacteria including S. pneumoniae (41) and H. influenza (42). It is attractive to speculate that CRP fills this immunological niche and provides partial protection from infection in individuals bearing the R-131 allotype of Fc $\gamma$ RIIa.

Analysis of the relative binding avidities of CRP to monocytes and PMN demonstrates a lower avidity of binding to cells from heterozygous H-131/R-131 donors as compared with cells from R-131 homozygotes. Thus, CRP binding to FcyRIIa is dependent on the level of expression of the FcyRIIa R-131 allotype. One possible explanation for the difference in avidity of CRP binding to cells from R-131/R-131 and R-131/H-131 individuals is that CRP binding to FcyRIIa is cooperative. The stoichiometry of CRP interaction with Fc $\gamma R$ RIIa has not been determined. CRP is a pentamer with 5 identical subunits potentially capable of interacting with FcyR. It is possible that CRP can interact with multiple FcyR leading to enhanced avidity. The binding avidities of CRP for monocytes from R-131 homozygous and R-131/H-131 heterozygous donors were 24 and $75 \mu \mathrm{g} / \mathrm{mL}$, respective- ly. These values are in the range of CRP concentrations present in sera from patients with mild to moderate acute phase responses (43).

FcyRIIa is unique among receptors using the immunoreceptor tyrosine activation motif (ITAM). Unlike other $\mathrm{Fc}$ receptors, the B-cell receptor complex and the CD3 complex, FcyRIIa is a single-chain receptor that can bind ligands and induce intracellular signaling events with an ITAM motif in the cytoplasmic domain (44). Responses induced by the crosslinking of this receptor include initiation of the oxidative burst, degranulation, cytokine production, and phagocytosis. The ability of CRP to induce a $\mathrm{Ca}^{2+}$ transient in PMN, which is required for many Fc $\gamma$ RIIa-induced functions, suggests that CRP binding to Fc $\gamma R I I a-R-131$ mimics binding of crosslinked IgG. These data suggest that CRP, because of its pentameric structure, can crosslink Fc $\gamma R$ on the cell surface. In vivo, CRP forms aggregates with various antigens because of its $\mathrm{Ca}^{2+}$-dependent ligand-binding sites that further enhance its ability to cross-link cell surface Fc $\gamma$ R.

Although we previously demonstrated CRP binding to FcyRI on monocytic cell lines and transfected COS cells, we found reduced CRP binding to leukocytes from FcyRIIa H-131 homozygous donors. However, peripheral blood PMN do not express Fc $\gamma \mathrm{RI}$, and monocytes express Fc $\gamma \mathrm{RI}$ at low levels. The levels of FcyRI on both monocytes and PMN are increased by cytokines such as IFN- $\gamma$ (23). Increased binding of CRP to monocytes from $\mathrm{H}-131 / \mathrm{H}-131$ donors after culture in IFN- $\gamma$ was observed. Thus, the lack of CRP binding to Fc $\gamma R \mathrm{R}$ in these cells is related to the low affinity of CRP for FcyRI as well as the low level of expression of FcyRI in resting monocytes and PMN. In these experiments, we also observed enhanced CRP binding to FcyRIIa after pro-

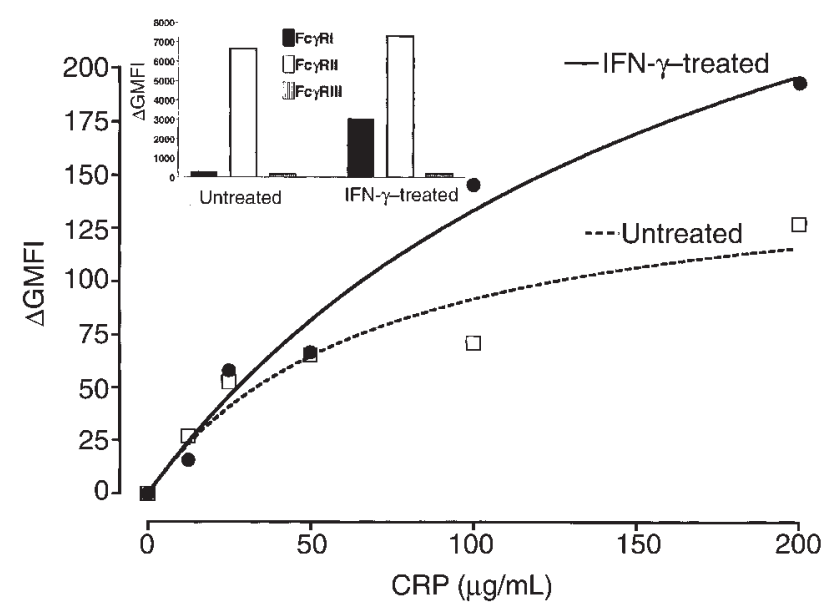

\section{Figure 6}

CRP binding to monocytes from $\mathrm{H}-131 / \mathrm{H}-131$ donors is enhanced by treatment with IFN- $\gamma$. Mononuclear cells from $\mathrm{H}-131$ homozygous donors were cultured for 48 hours in the presence or absence of 200 $\mathrm{U} / \mathrm{mL}$ of IFN- $\gamma$. Cells were collected, washed, and assayed for CRP binding using mAb 2C10 and PE-GAM. Results are expressed as the change in GMFI. The inset shows Fc $\gamma \mathrm{R}$ levels in cells cultured for 48 hours in the presence or absence of $200 \mathrm{U} / \mathrm{mL}$ of IFN- $\gamma$. 
tease treatment of cells, which suggests that conditions at inflammatory sites may upregulate CRP binding to both receptors. A similar role for inflammatory cytokines and proteolytic enzymes at sites of acute inflammation has been proposed as a mechanism for upregulation of immune complex binding to inflammatory cells (45). However, the differences in allotypes seen in resting cells were not eliminated by activation. Additional studies will be needed to establish the relative importance of CRP binding to Fc $\gamma \mathrm{RI}$ and Fc $\gamma \mathrm{RIIa}$ during the acute phase response and at inflammatory sites where levels of FcyRI may be greatly elevated.

\section{Acknowledgments}

We thank Ka Chen, Jamie Bender, and Michael Volzer for excellent technical assistance. This work was supported in part by the Department of Veterans Affairs and by National Institutes of Health grants AI28358, AR42476, and P50 AR45231.

1. Szalai, A.J., Agrawal, A., Greenhough, T.J., and Volanakis, J.E. 1997. Creactive protein structural biology, gene expression, and host defense function. Immunol. Res. 16:127-136.

2. Osmand, A.P., et al. 1977. Characterization of C-reactive protein and the complement subcomponent $\mathrm{C} 1 \mathrm{t}$ as homologous proteins displaying cyclic pentameric symmetry (pentraxins). Proc. Natl. Acad. Sci. USA. 74:739-743.

3. Mortensen, R.F., Osmand, A.P., Lint, T.F., and Gewurz, H. 1976. Interaction of C-reactive protein with lymphocytes and monocytes: complement-dependent adherence and phagocytosis. J. Immunol. 117:774-781.

4. Kindmark, C.-O. 1971. Stimulating effect of C-reactive protein on phagocytosis of various species of pathogenic bacteria. Clin. Exp. Immunol. 8:941-948.

5. Kilpatrick, J.M., and Volanakis, J.E. 1985. Opsonic properties of C-reactive protein. Stimulation by phorbol myristate acetate enables human neutrophils to phagocytize C-reactive protein-coated cells. J. Immunol. 134:3364-3370.

6. Kaplan, M.H., and Volanakis, J.E. 1974. Interactions of C-reactive protein with the complement system. I. Consumption of human complement associated with the reaction of C-reactive protein with pneumococcal polysaccharide and with the choline phosphatides, lecithin and sphingomyelin. J. Immunol. 112:2135-2147.

7. Crowell, R.E., Du Clos, T.W., Montoya, G., Heaphy, E., and Mold, C. 1991. C-reactive protein receptors on the human monocytic cell line U-937. Evidence for additional binding to FcoRI. J. Immunol. 147:3445-3451.

8. Marnell, L.L., Mold, C., Volzer, M.A., Burlingame, R.W., and Du Clos T.W. 1995. C-reactive protein binds to FcgRI in transfected COS cells. J. Immunol. 155:2185-2193.

9. Tebo, J.M., and Mortensen, R.F. 1990. Characterization and isolation of a C-reactive protein receptor from the human monocytic cell line U-937. J. Immunol. 144:231-238.

10. Zeller, J.M., Kubak, B.M., and Gewurz, H. 1989. Binding sites for C-reactive protein on human monocytes are distinct from IgG Fc receptors. Immunology. 67:51-55.

11. Bharadwaj, D., Stein, M.P., Volzer, M., Mold, C., and Du Clos, T.W. 1999 C-reactive protein binds to FcgRIIA-transfected COS cells. J. Exp. Med. 190:585-590

12. Clark, M.R., Clarkson, S.B., Ory, P.A., Stollman, N., and Goldstein, I. 1989. Molecular basis for a polymorphism involving Fc receptor II on human monocytes. J. Immunol. 143:1731-1734.

13. Warmerdam, P.A.M., van de Winkel, J.G.J., Vlug, A., Westerdaal, N.A.C., and Capel, P.J.A. 1991. A single amino acid in the second Ig-like domain of the human Fcg receptor II is critical for human IgG2 binding. $J$. Immunol. 147:1338-1343.

14. Anderson, C.L., Ryan, D.H., Looney, J., and Leary, P.C. 1987. Structural polymorphism of the human monocyte 40 kilodalton Fc receptor for IgG. J. Immunol. 138:2254-2256.

15. Parren, P.W., et al. 1992. On the interaction of IgG subclasses with the low affinity FcoRIIA (CD32) on human monocytes, neutrophils and platelets. Analysis of a functional polymorphism to human $\operatorname{IgG}_{2}$. J. Clin. Invest. 90:1537-1546.
16. Du Clos, T.W., Zlock, L., and Marnell, L.L. 1991. Definition of a C-reactive protein binding determinant on histones. J. Biol. Chem. 266:2167-2171. 17. Gosselin, E.J., Brown, M.F., Anderson, C.L., Zipf, T.F., and Guyre, P.M. 1990. The monoclonal antibody $41 \mathrm{H} 16$ detects the Leu 4 responder form of human FcgRII. J. Immunol. 144:1817-1822.

18. Wu, J., et al. 1997. A novel polymorphism of FcgRIIIa (CD16) alters receptor function and predisposes to autoimmune disease. J. Clin. Invest. 100:1059-1070.

19. Edberg, J.C., et al. 1997. Analysis of Fc gamma RII gene polymorphisms in Wegener's granulomatosis. Exp. Clin. Immunogenet. 14:183-195.

20. Kocher, M., Edberg, J.C., Fleit, H.B., and Kimberly, R.P. 1998. Antineutrophil cytoplasmic antibodies preferentially engage FcgRIIIb on human neutrophils. J. Immunol. 161:6909-6914.

21. Edberg, J.C., Lin, C.T., Unkeless, J.C., and Kimberly, R.P. 1995. The $\mathrm{Ca}^{2+}$ dependence of human Fc gamma receptor-initiated phagocytosis. J. Biol. Chem. 270:22301-22307.

22. Edberg, J.C., Moon, J.J., Chang, D.J., and Kimberly, R.P. 1998. Differential regulation of human neutrophil FcgRIIa (CD32) and FcgRIIIb (CD16)-induced Ca ${ }^{2+}$ transients. J. Biol. Chem. 273:8071-8079.

23. Guyre, P.M., Morganelli, P.M., and Miller, R. 1983. Recombinant immune interferon increases immunoglobulin G Fc receptors on culture human mononuclear phagocytes. J. Clin. Invest. 72:393-397.

24. Salmon, J.E., Edberg, J.C., Brogle, N.L., and Kimberly, R.P. 1992. Allelic polymorphisms of human $\mathrm{Fc}$ gamma receptor IIA and Fc gamma receptor IIIB. J. Clin. Invest. 89:1274-1281.

25. Salmon, J.E., Edberg, J.C., and Kimberly, R.P. 1990. Fcg receptor III on human neutrophils. Allelic variants have functionally distinct capacities. J. Clin. Invest. 85:1287-1295.

26. Mold, C., Nakayama, S., Holzer, T.J., Gewurz, H., and Du Clos, T.W. 1981. C-reactive protein is protective against Streptococcus pneumoniae infection in mice. J. Exp. Med. 154:1703-1708.

27. Szalai, A.J., Briles, D.E., and Volanakis, J.E. 1995. Human C-reactive protein is protective against fatal Streptococcus pneumoniae infection in transgenic mice. J. Immunol. 155:2557-2563.

28. Xia, D., and Samols, D. 1997. Transgenic mice expressing rabbit C-reactive protein are resistant to endotoxemia. Proc. Natl. Acad. Sci. USA. 94:2575-2580.

29. Heuertz, R.M., Dongyuan, X., Samols, D., and Webster, R.O. 1994. Inhibition of C5a des Arg-induced neutrophil alveolitis in transgenic mice expressing C-reactive protein. Am. J. Physiol. 266:L649-L654.

30. Du Clos, T.W., Zlock, L., Hicks, P.S., and Mold, C. 1994. Decreased autoantibody levels and enhanced survival of (NZB X NZW) $F_{1}$ mice treated with C-reactive protein. Clin. Immunol. Immunopathol. 70:22-27.

31. Gotschlich, E.C., and Edelman, G.M. 1967. Binding properties and specificity of C-reactive protein. Proc. Natl. Acad. Sci. USA. 57:706-712.

32. Volanakis, J.E., and Wirtz, K.W.A. 1979. Interaction of C-reactive protein with artificial phosphatidylcholine bilayers. Nature. 281:155-157.

33. Li, Y.P., Mold, C., and Du Clos, T.W. 1994. Sublytic complement attack exposes C-reactive protein binding sites on cell membranes. J. Immunol. 152:2995-3005.

34. Robey, F.A., Jones, K.D., Tanaka, T., and Liu, T.-Y. 1984. Binding of Creactive protein to chromatin and nucleosome core particles. A possible physiological role of C-reactive protein. J. Biol. Chem. 259:7311-7316.

35. Du Clos, T.W. 1989. C-reactive protein reacts with the U1 small nuclear ribonucleoprotein. J. Immunol. 143:2553-2559.

36. Stein, M.P., Mold, C., Bharadwaj, D., and Du Clos, T.W. 1999. C-reactive protein $(\mathrm{CRP})$ binding to murine peritoneal cells requires $\mathrm{Fc}$ receptors (FCR). FASEB J. 13:A281 (Abstr.)

37. Platonov, A.E., et al. 1998. Association of human FcgRIIa (CD32) polymorphism with susceptibility to and severity of meningococcal disease. Clin. Infect. Dis. 27:746-750.

38. Bredius, R.G.M., et al. 1994. Fc gamma receptor IIa (CD32) polymorphism in fulminant meningococcal septic shock in children. J. Infect. Dis. 170:848-853

39. Van der Pol, W.L., and van de Winkel, J.G.J. 1998. IgG receptor polymorphisms: risk factors for disease. Immunogenetics. 48:222-232.

40. Jefferis, R., and Kumararatne, D.S. 1990. Selective IgG subclass deficiency: quantification and clinical relevance. Clin. Exp. Immunol. 81:357-367.

41. Tillett, W.S., and Francis, T., Jr. 1930. Serological reactions in pneumonia with a non-protein fraction of pneumococcus. J. Exp. Med. 52:561-571.

42. Weiser, J.N., et al. 1998. Phosphorylcholine on the lipopolysaccharide of Haemophilus influenzae contributes to persistence in the respiratory tract and sensitivity to serum killing mediated by C-reactive protein. J. Exp. Med. 187:631-640.

43. Ballou, S.P., and Kushner, I. 1992. C-reactive protein and the acute phase response. Adv. Intern. Med. 37:313-336.

44. Daeron, M. 1997. Fc receptor biology. Annu. Rev. Immunol. 15:203-234.

45. Tax, W.J.M., and van de Winkel, J.G.J. 1990. Human Fc gamma receptor II. A standby receptor activated by proteolysis? Immunol. Today. 11:308-310. 